\title{
Lack of efficacy of hydroxychloroquine in covid-19
}

\author{
Studies in mild-to-moderate cases as well as severe disease leave us still searching for a magic \\ pill
}

\author{
Joseph M Vinetz professor
}

Section of Infectious Diseases, Department of Internal Medicine, Yale University School of Medicine, New Haven, CT 06520-8022, USA

Some have trumpeted the 4-aminoquinoline antimalarial drugs, chloroquine and hydroxychloroquinine, for the treatment of covid-19, based on the (literally) incredible results of efficacy in reported uncontrolled trials. ${ }^{12}$ Two linked studies, ${ }^{34}$ however, add to an increasing body of evidence that these drugs lack virological or clinical efficacy in the treatment of covid- $19,{ }^{5}$ and might even be harmful. ${ }^{67}$

Because 4-aminoquinolines block endosomal acidification, this drug class has long been looked at for potential antiviral effect. ${ }^{8}$ Didier Raoult and colleagues in Marseilles used uncontrolled observations to claim that hydroxychloroquine (whether or not combined with the antibacterial azithromycin) is effective in treating covid-19. ${ }^{12}$ Further, Raoult has asserted that using placebo controls is unethical in times of plague and pestilence. ${ }^{29}$ Picking up on such themes, politicians with no expertise in science, medicine, or public health, supported by certain media, have picked up on the use of antimalarials as magic pills for the covid-19 pandemic. Rick Bright, former director of the US Department of Health and Human Services' Biomedical Advanced Research and Development Authority, was moved from his post after resisting calls for widespread immediate dissemination of such drugs. ${ }^{10}$

The two new studies in TheBMJ do not support the use of 4-aminoquinolines in covid-19. The first, an open label randomized trial of high dose hydroxychloroquine in mildly to moderately ill patients with covid-19 admitted to 16 government hospitals in China, showed no difference in virological endpoint at 28 days between groups treated with hydroxychloroquine versus standard care. ${ }^{3}$ The endpoint was time to negative conversion of SARS-CoV-2 on real time reverse transcription polymerase chain reaction (RT-PCR) tests on either an upper or lower respiratory sample (not specified), but viral loads were not quantified. No patients died and adverse effects were reported as minimal (electrocardiographic details were not provided).

The second study was an observational controlled study of patients with radiographically demonstrated covid-19 pneumonia requiring oxygen in French hospitals. ${ }^{4}$ Hydroxychloroquine was dosed at $600 \mathrm{mg}$ daily and the primary outcome was transfer to intensive care. Survival at 21 days with or without acute respiratory distress syndrome did not differ between the groups treated with hydroxychloroquine versus standard care. Eight of 84 patients receiving hydroxychloroquine had the drug stopped because of electrocardiogram changes. These authors concluded that hydroxychloroquine in moderately ill patients with covid-19 was not useful, perhaps even harmful.

Physicians and patients alike are desperate to use any possible drug for otherwise untreatable covid-19, and there is considerable political pressure as well. Hundreds of clinical trials of potential treatments for covid-19 are now registered on clinicaltrials.gov. While inpatient treatments such as remdesivir, convalescent plasma, and immunomodulators are undergoing formal clinical trials, testing of outpatient treatments lags. The few currently registered trials for outpatients are of interventions including pegylated interferon $\lambda$ (by single subcutaneous injection), oral favipiravir, and oral camostat mesylate, with clinical and virological outcomes. And, of course, there is hydroxychloroquine, the unproven and probably harmful drug that the US president is currently taking for post-exposure prophylaxis. The largest and most systematic outpatient trial is leveraged by the US National Institutes of Health through its AIDS Clinical Trials Group national network, funded by the National Institute of Allergy and Infectious Diseases. This randomized, placebo controlled, double blind trial includes an estimated 2000 outpatients with early covid-19, testing hydroxychloroquine plus azithromycin versus placebo in preventing hospital admission and death due to covid-19. ${ }^{11}$

The search for a magic pill against covid-19 continues. What would that look like? First, we need to treat symptomatic infection and prevent hospital admission and severe disease. Second, we need to give prophylaxis to individuals with high risk exposures such as healthcare workers and essential workers with high levels of public exposure. Finally, and much less probably, a widely usable, safe, and cost effective magic pill might even eradicate SARS-CoV-2, which has no known reservoir other than humans at this time. Outpatient platforms for carrying out systematic trials aimed at identifying safe and effective oral drugs for early infection with SARS-CoV-2 drugs are needed now. 
Competing interests: The BMJ has judged that there are no disqualifying financial ties to commercial companies.

Provenance and peer review: Commissioned; not peer reviewed.

1 Gautret P, Lagier JC, Parola P, etal Clinical and microbiological effect of a combination of hydroxychloroquine and azithromycin in 80 covid- 19 patients with at least a six-day follow up: A pilot observational study. Travel Med Infect Dis 2020;34:101663. 10.1016/j.tmaid.2020.101663 32289548

2 Million M, Lagier JC, Gautret P, etal . Early treatment of covid-19 patients with hydroxychloroquine and azithromycin: a retrospective analysis of 1061 cases in Marseille, France. Travel Med Infect Dis 2020:101738. 10.1016/..tmaid.2020.101738 32387409

3 Tang W, Cao Z, Han M, etal . Hydroxychloroquine in patients with mainly mild to moderate coronavirus disease 2019: open label, randomised controlled trial. BMJ 2020;369:m1849. 10.1136/bmj.m1849 32409561

4 Mahévas M, Tran V-T, Roumier M, etal . Clinical efficacy of hydroxychloroquine in patients with covid-19 pneumonia who require oxygen: observational comparative study using routine care data. BMJ 2020;369:m1844. 10.1136/bmj.m1844 32409486

5 Geleris J, Sun Y, Platt J, etal . Observational study of hydroxychloroquine in hospitalized patients with covid-19. N Engl J Med 2020. 10.1056/NEJMoa2012410 32379955

6 Magagnoli J, Narendran S, Pereira F, et al. Outcomes of hydroxychloroquine usage in United States veterans hospitalized with covid-19. medRxiv [Preprint] 2020. https://doi.org/10.1101/2020.04.16.20065920.
7 Borba MGS, Val FFA, Sampaio VS, et al. Chloroquine diphosphate in two different dosages as adjunctive therapy of hospitalized patients with severe respiratory syndrome in the context of coronavirus (SARS-CoV-2) infection: Preliminary safety results of a randomized, double-blinded, phase llb clinical trial (CloroCovid-19 Study). medRxiv [Preprint] 2020. https://doi.org/10.1101/2020.04.07.20056424.

8 Ferner RE, Aronson JK. Chloroquine and hydroxychloroquine in covid-19. BMJ 2020;369:m1432.

9 Sayare S. He was a science star. Then he promoted a questionable cure for covid-19. 2020. https://www.nytimes.com/2020/05/12/magazine/didier-raoult-hydroxychloroquine. html.

10 Florko N. Director of US agency key to vaccine development leaves role suddenly amid coronavirus pandemic. 2020. https://www.statnews.com/2020/04/21/rick-bright-out-atbarda/.

11 Clinicaltrial.gov. Evaluating the efficacy of hydroxychloroquine and azithromycin to prevent hospitalization or death in persons with covid-19. 2020. https://clinicaltrials.gov/ct2/show/ NCT04358068.

12 National Institutes of Health. NIH begins clinical trial of hydroxychloroquine and azithromycin to treat covid-19. 2020. https://www.nih.gov/news-events/news-releases/ nih-begins-clinical-trial-hydroxychloroquine-azithromycin-treat-covid-19.

Published by the BMJ Publishing Group Limited. For permission to use (where not already granted under a licence) please go to http://group.bmj.com/group/rights-licensing/ permissions 